\title{
AS ORIGENS DO ROMANCE-FOLHETIM: DO ESPAÇO TEXTUAL AO RECORTE DE UMA OBRA DE FICÇÃO
}

THE ORIGINS OF THE SERIAL: FROM TEXTUAL SPACE

TO THE TRIMMING OF A WORK OF FICTION

\author{
Jean-Yves Mollier \\ Université de Versailles Saint-Quentin-en-Yvelines \\ Versalhes - França \\ ORCID 0000-0003-3853-8247
}

\begin{abstract}
Resumo
Este artigo explora as mudanças ocorridas na literatura francesa no século XIX a partir da criação do folhetim enquanto espaço textual dedicado à crítica, situado no rodapé dos jornais, até a criação de um novo gênero literário: o romance-folhetim. Este novo modo de conceber a ficção, ritmado pela publicação cotidiana dos jornais, contribuiu para a expansão do público leitor e do mercado editorial, promovendo, assim, a popularização da literatura. Por outro lado, suscitou reaçóes da crítica que, não admitindo a relação entre a literatura e o dinheiro, preferiu desqualificá-la, tachando-a de "literatura industrial". Analisam-se aqui dois exemplos da época que denunciaram esse novo tipo de produção literária: um panfleto e um romance que atacam Alexandre Dumas e Honoré de Balzac. O artigo destaca igualmente que diferentes suportes, ritmos de publicação, formatos e preços são fatores determinantes para a recepção de uma obra.
\end{abstract}

Palavras-chave: romance-folhetim; jornais; modos de publicação; modos de recepção; materialidade do texto.

\section{Abstract}

This article explores the changes that occurred in French literature in the $19^{\text {th }}$ century, from the creation of the feuilleton as a textual space dedicated to criticism, located in the footer of newspapers, until the invention of a new literary genre: the serial. This new way of conceiving fiction, mensurable by the daily publication of newspapers, contributed to the expansion of readership and the publishing market, thus promoting the popularization of

\section{Résumé}

Cet article discute les changements survenus dans la littérature française du $\mathrm{XIX}^{\mathrm{e}}$ siècle à partir de l'usage d'un espace textuel situé au "rez-de-chaussée" de la page des journaux, consacré aux articles de critique, et qui accueillit un nouveau genre littéraire: le roman-feuilleton. Ce nouveau mode de concevoir la fiction, rythmé par la publication quotidienne des journaux, contribua à l'accroissement du lectorat et du monde de l'édition, et par tant à la populari- 
literature. On the other hand, it provoked reactions from critics who, not admitting the link between literature and money, preferred to dismiss the serial as "industrial literature". Here we analyze two $19^{\text {th }}$-century examples that denounced this new type of literary production: a pamphlet and a novel that attacked Alexandre Dumas and Honoré de Balzac. The article also emphasizes that different material forms, publication frequency, formats and prices are determining factors for the reception of a work.

Keywords: serial; newspapers; publication; reception; text materiality. sation de la littérature. Par ailleurs, ce genre entraîna des réactions contraires de la critique qui lui colla l'étiquette de "littérature industrielle". Deux textes de cette époque qui dénigrent ce nouveau type de production littéraire sont analysés: un pamphlet et un roman attaquant Alexandre Dumas et Honoré de Balzac. Cet article souligne en outre le fait que les différents supports, rythmes de publication, formats de livre et prix de vente représentent des facteurs qui guident la réception d'une œuvre littéraire.

Mots-clés: roman-feuilleton; journaux; modes de publication; modes de réception; matérialité du texte.

Como já é sabido hoje em dia, de início o folhetim foi um espaço jornalístico (GUISE, 1975)'1 aquilo que podemos chamar de "casa textual", antes de se transformar em um verdadeiro gênero literário (THERENTY; VAILLANT, 2001; THERENTY, 2003, 2007). Esta mutação - a passagem do folhetim-romance ao romance-folhetim - deu-se em cerca de trinta anos (DUMASY, 1989), em um ritmo que se acelerou nos dez anos anteriores à introduçáo maciça de ficçôes nos jornais franceses. O que antes era apenas uma seção dedicada à crítica teatral, musical ou científica, ou ainda à crítica dos "romances de novidade", o folhetim vai transformar totalmente os hábitos dos franceses e impor novas maneiras de ler, além de contribuir a um só tempo para o declínio dos gabinetes de leitura (PARENT-LARDEUR, 1981) e o florescimento das livrarias-editoras. Apesar de tais modificaçôes na infraestrutura sociocultural da França terem levado um certo tempo - em diferentes ritmos em Paris e na província -, em alguns anos passa-se de um regime de apropriação do romance a um outro, e no início do século XIX ocorreu com o romance francês o mesmo que havia ocorrido com o teatro no século anterior na Inglaterra. A modificaçáo do suporte de leitura havia acarretado uma mutaçáo

1 Esta tese, fundamental para o estudo do romance-folhetim, infelizmente é inédita. 
radical do "sentido" das obras, e um autor como William Congreve havia mudado verdadeiramente de público, graças à reedição de suas comédias em um novo formato, e conforme outros dispositivos de apresentação (McKENZIE, 1991).

Mesmo que provavelmente náo seja possível transpor automaticamente as análises de Donald F. McKenzie de um gênero literário para outro, é possível indagar sobre a distância que separa a leitura de um romance publicado diariamente em folhetim - e muitas vezes com interrupçóes - da leitura da mesma obra fabricada especialmente para o público dos gabinetes de leitura - dois ou três volumes com diagramação muito arejada, com formato in- 8 - ou, ao contrário, para a clientela das livrarias, em um pequeno volume compacto, o "formato Charpentier", um in-18 que prevalece a partir de 1838 (MOLLIER, 2015, cap. VII). As modificaçóes da composição dos volumes, o formato que varia em funçáo dos diversos grupos de leitores, seu preço, todos esses dispositivos externos impactam profundamente a recepçáo e modificam sem dúvida alguma o regime de leitura. Que Gustave Flaubert tenha imediatamente compreendido isso ou não, a publicação de Madame Bovary na Coleção Michel Lévy, em 1857, com o volume sendo vendido a 1 franco, desviou a obra de seu público "natural" - algumas centenas ou milhares de leitores cultos e abastados - e facultou a aceleração das vendas - 25.000 volumes em um ano (MOLLIER, 1984, p. 341-346). Este abrupto e expressivo crescimento da demanda faz de Gustave Flaubert, imediatamente, um "escritor da moda", procurado pelo leitor por causa do conteúdo pernicioso de suas obras e, por sua recepção, próximo de um Ernest Feydeau, autor de Daniel e de Fanny, romances que hoje ninguém compararia a Madame Bovary.

Augustin Sainte-Beuve não esperou pela generalização do fenômeno do romance-folhetim para publicar, em setembro de 1839 , seu explosivo artigo intitulado De la littérature industrielle, e em 1845 Alexandre Dumas e Honoré de Balzac já eram sistematicamente atacados pelos caricaturistas. Alexandre Dumas era o alvo do panfleto Fabrique de romans. Maison Alexandre Dumas et Compagnie, assinado por Eugène de Mirecourt, jornalista e polígrafo, enquanto Honoré de Balzac tinha sido transformado por Louis Reybaud em personagem de um romance-folhetim, Les Idoles d'argile, publicado pelo jornal 
Le National, antes de aparecer em formato de livro, com um título levemente modificado, César Falempin ou les idoles d'argile par l'auteur de Jérôme Paturot (César Falempin ou..., 1845). Verdadeiro inventor do "folhetim a vapor", o autor da Comédie Humaine surgia com os contornos de um empreendedor, schumpeteriano avant la lettre, que havia compreendido seu século, em tempos de vapor e velocidade, e decidiu utilizar a divisão científica do trabalho para dar aos leitores a porção de sonho ou de imaginação que supunha corresponder às suas preferências. Uma vez que o jornal havia transformado a vida dos franceses, a ponto de não se poder ser bem-sucedido nos negócios sem ser dono de um jornal diário, Jules Granpré, o manager do romance de Louis Reybaud, era obrigado a dobrar-se às exigências do momento e usar, ele também, o jornal e seu folhetim romanesco para alcançar seus propósitos e vender as açôes de sua mirabolante sociedade, a Compagnie Péninsulaire, que daria à Espanha uma linha de trens ligando os Pirineus a Gibraltar.

Para além daquilo que caracteriza a intriga de um romance-folhetim, que hoje em dia ninguém mais lê - porque até mesmo a obra mais conhecida de Louis Reybaud, Jérôme Paturot à la recherche d'une position sociale, se perdeu no esquecimento da história literária ${ }^{2}$ -, o que nos interessa aqui é seu modo de publicaçáa. Com efeito, o romance foi segmentado em fascículos, entregues mais ou menos diariamente para publicaçáo, antes de ser publicado, a seguir, em volume, e vendido nas livrarias; o que pressupóe que são visados dois tipos de público com hábitos - e talvez com habitus - radicalmente distintos. O recorte em 29 capítulos - os mesmos equitativamente distribuídos entre os dois tomos que compóem a obra, comportando o primeiro volume 333 páginas e no segundo 334 páginas - requer ser estudado atentamente, por provavelmente corresponder àquilo que se supunha que um leitor ideal de um jornal diário parisiense de grande circulaçáo poderia absorver a cada dia, ou pelo menos nos dias da semana em que era publicado o romance-folhetim. A leitura do National, do Constitutionnel, do Journal des Débats, de La Presse ou do Siècle mostra, com efeito, que a publicação da ficção alterna, conforme regras precisas, com a publicação às segundas-feiras de uma

2 O romance, no entanto, foi republicado em 1997 por Sophie-Anne Leterrier, pela editora Belin (Paris). 
crônica teatral, às terças, quartas e quintas de uma crônica musical, literária ou científica, sendo o final de semana, de preferência, reservado às publicaçóes do romance, cuja missáo era a de satisfazer o desejo de evasão dos leitores.

\section{O primeiro folhetim a vapor}

Em fevereiro de 1845, pivô de um imenso maquinário que entáo funciona em sua plena capacidade, Alexandre Dumas havia sido vítima de um ataque violento destinado a desvalorizar sua produção e a revelar ao grande público a descarada exploração de um exército de ghost writers. Para o redator de Fabrique de romans. Maison Alexandre Dumas et Compagnie, o verdadeiro autor de Trois Mousquetaires não era Alexandre Dumas mas Auguste Maquet, a quem ele se referia como "o chefe da manufatura" (MIRECOURT, 1845, p. 45), a empresa que, por conseguinte, assina o romance, ou, em outras palavras, para continuar com a mesma metáfora, aquele que estampilha sua "marca" ou carimba o produto fabricado em série. No mesmo momento, Louis Reybaud, o autor de Jérôme Paturot à la recherche d'une position sociale, um imenso sucesso do ano de 1843, publicava um romance inicialmente intitulado Les Idoles d'argile, mas que foi a seguir rebatizado com o título de César Falempin ou les idoles d'argile para integrar o catálogo da editora Michel Lévy Irmãos. É preciso ressaltar que seus editores, para anunciar suas futuras publicaçóes, ainda utilizam a fórmula reservada aos livros destinados aos gabinetes de leitura, "pelo autor de Jérôme Paturot", e não de seu patronímico, o que situa sua entrada na cena midiática em um momento crucial da história. Com efeito, seu estudo de costumes é publicado no exato instante em que a apropriação direta das obras em volumes com uma diagramação muito arejada, tendo como intermediário o gabinete de leitura, é substituída por uma outra forma de leitura, fragmentada e, desta feita, embalada pelo ritmo de publicação dos folhetins na imprensa.

Louis Reybaud, que o público conhecia como jornalista e observador social, acabara de publicar na Revue des Deux Mondes uma série de artigos posteriormente reunidos com o título de Études sur les réformateurs ou socialistes modernes, que lhe abriram as portas do 
Instituto de França e também as da Câmara dos Deputados, em que ele tomou assento em 1846. A revolução de 1848 não o surpreendeu, mas ele recusou suas mudanças de rumo; e, com Jérôme Paturot à la recherche de la meilleure des Républiques, igualmente publicado em folhetins e depois em volumes, e finalmente com uma série agressiva de ilustraçóes que aumentaram sua difusão, ele se tornou o pintor da reação antissocialista (MOLLIER, 1984, p. 73-75; 142-147). Duríssimo com George Sand - a musa de Ledru-Rollin, e na opiniáo de seus detratores a grande sacerdotisa da revoluçáo -, e igualmente duro com todos os fazedores de sistemas que haviam tentado tirar proveito dos acontecimentos para solucionar a questão social, Louis Reybaud demonstrava a seu modo a mutação que levara a imprensa a invadir o campo literário ou a literatura a invadir o campo midiático (THÉRENTY, 2003; KALIFA et al., 2011). Uma vez que a distinção entre esses dois campos era cada vez menos evidente - como se percebeu em 1842-1843, quando os leitores de Les Mystères de Paris transformaram Eugène Sue em reformista e rapidamente em socialista, representando os interesses do povo parisiense (GALVAN, 1998; LYON-CAEN, 2006) -, as fronteiras entre os dois universos tendiam a esmaecer, e a literatura invadia a vida, alterando completamente as práticas culturais e prenunciando a cultura de massa que vai prosperar depois de 1860 ou 1880 (KALIFA, 2001; MOLLIER, 2002, p. $72-$ 115; MOLLIER; SIRINELLI; VALLOTTON, 2006).

O sucesso de Jérôme Paturot, um autêntico tipo social da Monarquia de Julho, confirmava o talento daquele que, em César Falempin, havia produzido a análise mais acurada do fenômeno do romance-folhetim. Ilustrado pelo acontecimento que foram, em 1842-1843, a publicação no Journal des Débats de Les Mystères de Paris de Eugène Sue, e no ano seguinte a publicação do Comte de Monte-Cristo, de Alexandre Dumas, este gênero literário estava revolucionando os modos de ler e impondo sua supremacia ao mundo inteiro. Com efeito, como foi acertadamente notado por Peter Brooks (2011), foi por meio da exportação da "imaginação melodramática" que a França bateu os outros países, e até mesmo a Inglaterra - na qual, entretanto, se originou com Walter Scott e Charles Dickens um movimento que levaria progressivamente o romance a suplantar a poesia e o teatro (MORETTI, 2000). Para além do conteúdo das obras de ficção e 
de suas temáticas, a maneira de levá-los ao conhecimento do público estava mudando sua recepção e provocando modificaçôes em seu modo de escrita, as quais não haviam passado despercebidas aos olhos de Louis Reybaud. Em vez de utilizar a forma do ensaio e de deixar à discrição da revista de François Buloz o cuidado de divulgar suas análises - como havia feito em relação aos reformadores sociais -, com Les Idoles d'argile, Louis Reybaud optou pela via do romance para encenar a primeira "manufatura de folhetins" concebida por uma mente empreendedora, e levar seu leitor a percorrer as entranhas de seu universo mecânico.

Dividido em 29 capítulos e publicado em dois volumes na versão chamada de gabinete de leitura, posta à venda por Michel Lévy em maio ou junho de $1845^{3}$, o romance descrevia o comportamento de Jules Granpré, um homem de negócios sem muitos escrúpulos e firmemente decidido a espoliar seus contemporâneos para satisfazer suas ambiçóes. Após ter fundado uma Companhia Peninsular, destinada a levantar o máximo de fundos, e ter tirado proveito de deputados e ministros para consolidar sua empresa, ele se volta para a imprensa e a propaganda comercial, a fim de dar à sua sociedade fundações mais sólidas. Com o argumento de que "o jornal é necessário para que o folhetim seja consumido", Jules Granpré se propóe a lançar seu próprio jornal diário, Le Phénix, fazendo com que Le Mistigris romance segmentado em duzentos e quarenta episódios que o ferreiro das letras David vai fabricar para ele em uma usina situada perto da Étoile - seja o carro-chefe de sua estratégia de captação de assinantes; o endereço da usina não deixa nenhuma dúvida quanto à identidade do administrador, Honoré de Balzac, que vivia naquele momento na rua Raynouard, em Passy (César Falempin ou..., 1845, t. I, cap. X e $\mathrm{XI})$.

Apoiando-se, sem o citar, no artigo de Sainte-Beuve publicado na Revue des Deux Mondes de setembro de 1839 e intitulado De la littérature industrielle, Louis Reybaud fazia de Alexandre Dumas um mero amador e alçava Balzac à posição de verdadeiro inventor do "folhetim a vapor". Assim, após ter levado seu leitor à lojinha de Alexandre Dumas - o qual havia acabado de assinar um contrato para

3 O romance é anunciado com atraso, como ocorre frequentemente na Bibliographie de la France, em 9 de agosto de 1845. 
entregar um romance de 200.000 linhas, remuneradas a 75 centavos a linha, e que, portanto, não tinha tempo disponível para se dedicar a mais uma encomenda -, Jules Granpré vai bater à porta de David, um dos quatro "ferreiros das letras", que o recebe em sua "Manufatura de Folhetins" (César Falempin ou..., 1845, t. I, p. 232). Depois de levá-lo para visitar sua usina, David propóe a Jules Granpré que escolha seu tipo de folhetim com base em uma amostragem, pois ele dispóe de folhetins "de todos os preços e para todas as preferências" (p. 234-235). Envaidecido por poder expor seus talentos e destacar a originalidade de sua fábrica de romances, ele exclama:

Ó meus confrades de folhetim, lutarei bravamente contra os senhores! Dizem que os senhores praticam um comércio de pequeno varejo, que promovem um trabalho doméstico e que, depois, os senhores estampilham a mercadoria com seu selo! Procedimentos pobres! Meios mesquinhos! Em breve, os senhores verão o que significa trabalhar por atacado e a vapor! O economista Adam Smith afirma que o alfinete só alcançou a perfeição a partir do dia em que foram necessários dez homens para fabricá-lo. Darei a vinte homens a tarefa de escrever o folhetim e o resultado será uma maravilha. (p. 236)

Após ter aceitado as propostas de Jules Granpré, David-Honoré de Balzac exibe, para que ele a admire, a enorme máquina a vapor que alimenta sua empresa e os 50 cubículos numerados de 1 a 51, nos quais estão trancados outros tantos escritores, recrutados em função de sua especialização:

Isto aqui representa um folhetim completo, dividido em capítulos. Quando acho um homem que possui o sentimento da natureza e descreve bem paisagens, eu o coloco no cubículo da paisagem. Aquele que tem uma pena sensível entra no cubículo do sentimento; aquele que possui o instinto do diálogo popular entra no cubículo do diálogo popular, e o mesmo ocorre com os outros. Cada um trata daquilo que sabe fazer melhor e, como afirma Adam Smith, deste modo, o folhetim alcança seu mais alto grau de aperfeiçoamento. (p. 237) 
Para otimizar sua produção e dar a seus operários condições de trabalho agradáveis, o engenhoso empreendedor fez instalar em cada cubículo um dispositivo que jogava ar quente nos pés e ar frio na face: "A cabeça fria e os pés quentinhos, este é o ideal que concretizei em minha manufatura" (p. 238), conclui o filantropo explorador dos talentos de seus semelhantes, que se recusa a abusar dos trabalhadores, e ao mesmo tempo vive da venda do produto de uma imaginação que não lhe pertence. Sendo igualmente discípulo de Bentham, ele concebeu sua "manufatura de Folhetins" como um panóptico; e, de sua mesa de trabalho colocada no centro da usina, ele puxa todas as cordas que o ligam aos cubículos, confessando com uma indisfarçável alegria: "Sem me mover desta poltrona, eu dirijo tudo, eu vigio tudo" (p. 239). Fica assim claro que, inventor do "primeiro folhetim a vapor" (p. 241), o David de César Falempin foi mais longe do que o David Séchard de Illusions perdues, e encontrou a solução para o problema que o artesão Alexandre Dumas apenas esboça quando faz trabalhar três ou quatro modestos ghost writers que o ajudam a ganhar o pão de cada dia. Com Balzac, é o mundo industrial que se descortina para o leitor, e somente um observador social que tivesse lido um grande número de teóricos socialistas da primeira metade do século XIX poderia realizar essa descrição, que antecipa, por alguns ângulos, aquele universo que, um século mais tarde, será descrito por Aldous Huxley em Admirável Mundo Novo. Desde então, cada um tem seu lugar, aquele que lhe foi designado pelo Leviatá moderno, e o romance não depende mais totalmente da imaginação de um único criador ou de dois ou três associados; ele agora é fabricado por tantos especialistas quantos forem exigidos por uma divisão de trabalho perfeitamente racional.

Mesmo que Les Idoles d'argile se tenha proposto a ser, como Jérôme Paturot à la recherche d'une position sociale, uma ficção recreativa e engraçada, a vontade didática do pintor da vida social transparecia a cada página, e as reviravoltas da intriga acompanhavam o novo ritmo que a segmentação em folhetins cotidianos imprimia a uma obra destinada a esse modo de publicação. Como já referido, existe uma espécie de hiato entre as duas formas de publicaçáo escolhidas, pois o volume de gabinete de leitura - recortado e com diagramação arejada, de modo a preencher a matéria de dois volumes in-8, quando 
um único pequeno in-18 compacto com o formato Charpentier teria bastado - pressupóe uma leitura que em nada se compara àquela dos folhetins. Os 29 capítulos do romance na versão impressa em dois tomos expressam, de modo imperfeito, o que o autor havia almejado fazer ao escrever para seus leitores do National, o importante jornal fundado por Adolphe Thiers, que estava a serviço de uma política conservadora.

\section{Um recorte da obra ritmado pelo movimento do jornal}

Como qualquer romance-folhetim que se preze, e cujo modelo naquele momento é o romance Les Mystères de Paris, Les Idoles d'argile é um melodrama que utiliza os arquétipos do Bem e do Mal para fazer surgir duas espécies de personagens, os bons e os maus. Neste caso, trata-se do general barão Dalincour e de seu antigo sargento das guerras do Império de Napoleão, o porteiro César Falempin. Este personagem, cujo nome aparece no título do romance publicado em volume, está firmemente decidido a proteger a filha do herói dos campos de batalha contra os maus-tratos de sua madrasta, Eléonore Dalincour, e de seu abominável cúmplice, Jules Granpré, "um quarto de corretor público", cuja imaginação está voltada exclusivamente para espoliar aqueles que alguns anos mais tarde serão chamados de "gogos" (patos). Lembrando, por alguns de seus aspectos, um conto de fadas - mas se distinguindo deste gênero por seu final em que morre a vítima, Emma Dalincour -, o romance de Louis Reybaud é um estudo de costumes que descreve as falhas daquele tempo e denuncia a seu modo os estragos provocados pelo dinheiro, num universo em que o sentido de honra, de fidelidade e de amor se tornaram inexpressivos. Como Balzac e Eugène Sue, Alexandre Dumas e muitos outros autores menos conhecidos, Louis Reybaud pretende prender a atenção do leitor por um efeito de suspense, e ao mesmo tempo lhe fornece os meios para melhor compreender seu século. Por seu viés didático, romance mais próximo de Les Mystères de Paris do que Le Père Goriot ou Illusions perdues, Les Idoles d'argile abraça as teses principais do jornal em que é publicado, a saber, um nacionalismo intransigente que associa o culto do grande imperador àquele do regime de Luís Filipe, rei dos franceses que reina ao abrigo da bandeira tricolor. 
Quando se observa atentamente a segmentação da obra em função de sua publicação em formato de folhetins, vê-se que estes, de modo geral, são publicados nos finais de semana, às sextas, aos sábados e aos domingos, já que os jornais diários não respeitam o descanso dominical. Tendo sido iniciada em 18 de janeiro de 1845 , um sábado, e encerrada na sexta-feira 14 de março, percebe-se que a publicaçáo frequentemente começa às quintas-feiras e prossegue nos três dias seguintes, sem que haja, contudo, uma completa regularidade. Apenas as segundas-feiras são sistematicamente reservadas ao folhetim dramático - ou seja, às representaçôes que ocorrem nos teatros parisienses -, as terças-feiras podendo ser dedicadas à revista musical dos espetáculos e as quartas-feiras às sessóes da Academia de Ciências. Eclético, mas levando em grande consideração as demandas de seus leitores, Le National é publicado em quatro páginas, sendo a última reservada - com uma proporção variável - aos anúncios que facultam o financiamento do jornal, enquanto a primeira página traz o comentário da atualidade política, nacional ou internacional, de acordo com as necessidades da conjuntura. Conforme a expressão já consagrada, o folhetim ocupa então o "rodapé do jornal" (THIESSE, 1984); porém, contrariamente ao que se tenderia a acreditar, ele não se limita a essa localização e invade amplamente o espaço interno do jornal. Com efeito, Les Idoles d'argile ocupa o último terço da primeira e da segunda página, a fim de dar ao leitor o conteúdo de um capítulo da edição do gabinete de leitura, mas que vem impressa em três colunas, tal como o jornal em seu conjunto, diferentemente do volume vendido em livraria ${ }^{4}$.

Uma única vez, para a inserção do capítulo XI, intitulado Quatro ferreiros das letras. Uma Manufatura de Folhetins, será necessário ocupar igualmente o último terço da terceira página, a fim de não romper o equilíbrio e trazer uma conclusão que não fosse um convite para ler a continuação "no próximo número" ou no dia seguinte. Previsto desde o início, de acordo com as regras ainda em vigor antes de 1848, para ser publicado a seguir em volume, o romance se apresenta

4 Comparativamente, ver a análise estrutural do jornal La Presse para o ano de $1836 \mathrm{em}$ THÉRENTY; VAILLANT, 2001, especialmente as páginas 60-78. O folhetim prolifera também da página 1 à página 2 ou 3, e o jornal de Girardin alterna o folhetim-romance e o folhetim dramático, musical ou científico. 
ostensivamente como um livro dividido em dois tomos e 29 capítulos, com sua indicação no início de cada folhetim. Para ser mais exato, "o autor de Jérôme Paturot" - pois esta é a assinatura aposta em cada folhetim - havia firmado com Michel Lévy um contrato para a venda de Pierre Mouton, em outubro de 1844, e depois um segundo contrato, em março de 1845, quando o editor comprou César Falempin e Le Dernier des commis voyageurs, o primeiro integralmente publicado nas colunas do National, desde a véspera, devendo o seguinte ser publicado ao longo do ano (Arquivos Calmann-Lévy, dossiê Louis Reybaud; MOLLIER, 1984, p. 74-75). Comprado pelo valor de 1.200 francos - ou seja, pelo equivalente a 6.000 euros -, o romance, que havia sido rebatizado César Falempin visando tirar vantagem da popularidade junto aos leitores desse herói das guerras napoleônicas que havia se tornado um "Monsieur Pipelet" cheio de recursos, teria uma tiragem reduzida de 600 exemplares, vendidos por 15 francos (dois tomos por 7,50 francos cada um) e estritamente destinados ao mercado dos gabinetes de leitura. Assim, muito concretamente, são desenhados os contornos de dois grupos de leitores que podem ser parcialmente superpostos; o primeiro é composto por leitores e leitoras do National, os quais, em sua maioria, não comprarão o volume para o conservar em sua biblioteca, nem tampouco irão ao gabinete de leitura para levar de empréstimo um dos tomos ou para ler in loco. É exatamente o que fará o segundo círculo de leitores: gastarão alguns centavos para satisfazer sua paixão e passar algumas horas bem aquecidos nessas vendas de leitura, ou para levar um dos volumes dedicados às aventuras de um melodrama que teria sido facilmente transposto para os palcos, caso um autor do "bulevar do crime" tivesse se interessado por ele.

Já que um dos ferreiros das letras, de certo modo, revela seu segredo ao afirmar que os autores dos romances-folhetim publicados pelos jornais mais importantes são remunerados a 75 centavos a linha, é fácil calcular que Louis Reybaud recebeu do National a bela soma de 6.525 francos, pois cada folhetim continha aproximadamente 50 linhas e ocupava três colunas em duas páginas. Pode-se, assim, calcular que um capítulo de um romance-folhetim equivalia a 300 linhas de um jornal, ou ainda era distribuído em 18 páginas de um volume de 21 linhas de 7 palavras, ou seja, em média 2.500 palavras. Se continuarmos a desenvolver este modesto raciocínio contábil, que qualquer 
folhetinista com alguma experiência dominava inteiramente $e^{5}$ uma página compreendia mais ou menos 150 palavras, e um capítulo 18 páginas, ou seja, aproximadamente 2.500 palavras. Esta é a base da remuneração dos autores, a qual acarreta, como se sabe, a tentação de multiplicar os diálogos e mudar de parágrafo, sendo que as reticências e os pontos de exclamação eram remunerados com o mesmo valor que qualquer palavra. Caso se prefira contabilizar caracteres ou "letras", como fazia Maupassant, cada linha comportava 50 caracteres, o que perfazia uma média de 1.000 caracteres por página ou 18.000 por capítulo, e 330.000 por tomo, ou seja, 660.000 caracteres em um romance. Contudo, se forem deduzidas dessa conta as muitas páginas em branco, intercaladas entre os capítulos, e se forem consideradas as páginas com duas ou três linhas em final de capítulo, há na composição de um romance uma média de 500.000 caracteres, ou seja, o conteúdo de um livro de bolso comum de nossos dias.

\section{De um recorte a outro ou como ler um romance-folhetim}

Não basta afirmar que não sabemos mais ler um romance-folhetim e que, por este motivo, somos hoje incapazes de apreender as obras do século XIX do modo como foram descobertas por seus contemporâneos. Mesmo nos esforçando para ler apenas um capítulo por dia e no final de semana, a fim de respeitar os ritmos impostos pelo jornal, não conseguiríamos recuperar os dispositivos mentais dos homens e das mulheres daquele tempo. Como foi brilhantemente demonstrado por Donald F. McKenzie, as formas produzem sentidos, e texto algum jamais chegou até nós senão em forma de livro impresso, com um determinado formato, ilustrado ou não, fabricado com um determinado papel agradável ao toque ou excessivamente seco, com um tipo de letra escolhido para chamar nossa atençáo ou não. Para dar apenas um exemplo, leitor algum de Madame Bovary, na edição da Bibliothèque de la Pléiade em papel-bíblia, dobraria os cantos das páginas ou escreveria comentários a caneta, enquanto o mesmo leitor

5 A correspondência de Maupassant fornece vários exemplos dessa prática. Ver uma carta de Maupassant datada de maio de 1889, endereçada ao diretor da Revue illustrée, na qual o escritor conta cada letra publicada, a fim de cobrar cada centavo devido pela revista (MAUPASSANT, 1973, t. III, p. 77-78). 
não hesitaria em maltratar a mesma página da edição de bolso, a qual se presta aparentemente a todos os tipos de mutilaçóes.

É vã, portanto, a esperança de desvelar completamente as estruturas mentais, ou como as refere Lucien Febvre (1947), as ferramentas que permitiam a um leitor do século XIX ingerir a prosa de um jornal que hoje consideramos indigesta por nos parecer grosseira, austera, se comparada à tipografia arejada e, melhor dizendo, elegante de um jornal de nossos dias ${ }^{6}$. Contudo, a segmentação dos romances-folhetim em sequências adaptadas a uma publicação cotidiana nos ajuda a penetrar nesta câmara escura. Cada capítulo de um volume, chamado de gabinete de leitura, constitui uma espécie de cena em tamanho reduzido, na qual as personagens dialogam entre si, fortalecendo a comparação com o teatro (COLIN; CONRAD; LEBLOND, 2013) e ressaltando a transmidialidade do gênero romanesco, propício a migrar de um suporte para outro (JENKINS, 2013) ${ }^{7}$. Melodramático, logo híbrido, e assumindo características tanto do teatro quanto do romance, próximo do conto como bem destacou René Guise (1975, t. I), povoado por arquétipos que remetem aos mitos e às lendas mais remotas (VAREILLE, 1994), o romance-folhetim constitui uma narrativa mista especialmente adaptada à fragmentação em episódios que sustentam o suspense e mantêm alerta a curiosidade do leitor. Como ressalta Alain Vaillant em seu estudo sobre a "poética da eloquência jornalística”, o que o leitor do jornal diário dos anos 1836-1848 parece querer

[...] não é ler um romance, mas ouvir contar uma história por um autor que, como o contador de histórias do salão ou ao pé da lareira, conhece todas as técnicas para manter a atenção: o ritmo veloz da narrativa, o recurso ao diálogo, a ironia ou, ao contrário, o patético e o espetacular, etc. (VAILLANT in THÉRENTY; VAILLANT, 2001, p. 106)

6 A primeira página de um jornal de 2017 comporta três ou quatro vezes menos caracteres do que seu homólogo de 1835-1845.

7 Remetemos igualmente a um colóquio fundador organizado por Jacques Migozzi e à sua introdução Fictions transmédiatiques: du rhizome au réseau (MIGOZZI, 2000, p. 7-24). 
Uma vez que a literatura invadiu o jornal e que a informação se dispersou na narrativa literária, existe uma relação permanente entre aquilo que se vincula ao fait divers, uma seção sistematicamente presente nos jornais a partir dessa época, e aquilo que é do âmbito da ficção. Devemos entáo concluir que o leitor passava de uma seção à outra sem uma pausa para respirar? Fica a dúvida, pois os filetes que separam o espaço textual destinado ao folhetim são nitidamente marcados, e o próprio título da seção, Folhetim, ou ainda, às vezes, Variedades, já nos anos de 1839-1840 induzia a presença de uma ficção, e, portanto, a introdução do leitor em um universo que não era o da realidade. Quanto a esse ponto, as análises de Richard Hoggart a respeito das leitoras britânicas dos anos 1950 (HOGGART, 1957) podem ser utilizadas e projetadas para 100 anos antes sem que haja grandes riscos de se incorrer em erro. A correspondência de Eugène Sue trocada com seus leitores, aliás, demonstra que, se estes se dirigem a ele como se ele fosse um reformista capaz de resolver os problemas do momento, eles náo deixam de conservar a certeza de que Les Mystères de Paris é um romance, acrescentando-lhe a esperança de que o romancista capaz de encenar essa ficção poderá, igualmente, encontrar os remédios apropriados aos flagelos que enfrenta a sociedade (GALVAN, 1998) ${ }^{8}$. Esta é provavelmente a razão pela qual sua eleiçáo como Representante do Povo em Paris, em 1850, é repleta de significados, e o poder o atacará encarniçadamente - a leitura de Les Mystères du Peuple foi proibida pela censura em 1857, enquanto que no mesmo ano apenas alguns poemas de Les Fleurs du Mal foram censurados (LECLERC, 1991).

Como é possível perceber, em duas ou três décadas o romance sofreu mutaçóes que decorrem, de início, do seu modo de difusão e, portanto, da sua recepçáo pelos leitores e, logo depois, da sua escrita; a popularidade do folhetim dedicado ao "romance de novidade", expressão típica daquela época, muito rapidamente convenceu os escritores a ceder à demanda, isto para não utilizar a mesma expressão que Sainte-Beuve, a ceder à encomenda. Mesmo que Balzac ainda pudesse exclamar, em 1829, "subscrevo ao in-12 mas gostaria de ser in-8”' (BALZAC, 1960, t. I, p. 366; MOLLIER, 1992, p. 157-173),

8 Para as cartas endereçadas pelos leitores de Eugène Sue ao Journal des Débats.

9 Carta de Balzac para Latouche, em 9 de janeiro de 1829. 
revelando assim as mais íntimas aspiraçóes de um jovem escritor que rejeita as limitaçóes do gabinete de leitura e deseja apaixonadamente "ser publicado" com o formato do belo volume exibido nos salóes da aristocracia e nas bibliotecas burguesas. Contudo, 10 anos mais tarde, ele acabou por aceitar as propostas de Gervais Charpentier e transformou seu modo de escrever para estar em conformidade com os horizontes de expectativa de seus leitores (GLEIZE, 2010, p. $97-$ 109).

Enquanto antes de 1800 tanto o romance quanto a poesia e o teatro pertenciam a um universo ainda relativamente fechado do ponto de vista social, a abertura das revistas à ficção pela via das pré-publicaçóes desde 1829-1831, notadamente na Revue de Paris, na Revue des Deux Mondes, em La Mode e L'Artiste ${ }^{10}$, e a seguir sua maciça introdução no folhetim dos jornais, transformaram completamente a recepção da literatura francesa. Mesmo que o fenômeno não seja um maremoto e que tenha havido muitas hesitaçóes antes de se recorrer sistematicamente ao folhetim para impor o jornal, conforme o método recomendado pelo David-Honoré de Balzac de Les Idoles d'argile, o reinado do "folhetim costurado a mão" (THIESSE, 1984) ia modificar as práticas culturais por um período bastante longo.

Por esse motivo, a segmentação da ficção em capítulos correspondendo à publicação de um livro com o formato dos gabinetes de leitura - o in-12 bem arejado em três volumes ao preço de 6 francos antes de 1830, o in-8 em dois ou três tomos por 7,50 francos após essa data ${ }^{11}$ - representa apenas um momento da história material do romance.

Vimos com César Falempin ou les idoles d'argile que Louis Reybaud havia trabalhado visando satisfazer dois públicos distintos e que seus capítulos correspondiam exatamente às seis colunas de um folhetim cotidiano publicado por um jornal de grande circulação. Quando os romancistas não mais tiverem a certeza de ter seus folhetins aceitos pelos editores, eles deverão dobrar-se às exigências externas, reduzir seu folhetim às dimensões das quatro ou cinco colunas do "rodapé", que lhes será doravante reservado, e a passagem

10 Para o estudo da genealogia do fenômeno, ver THÉRENTY; VAILLANT, 2001; e principalmente GUISE, 1975.

11 Esta distinção não é uma regra absoluta, mas antes uma tendência. 
para o volume vendido nas livrarias acarretará reescritas ou "costuras" correspondendo à nova segmentação. Logo, se não há modelo ou "molde" único de um capítulo de romance típico do século XIX, para continuar com a metáfora apreciada por costureiras e alfaiates, devemos insistir naquilo que nos ensina Donald Francis McKenzie: se é verdade que as formas produzem o sentido, entâo o recorte dos romances em capítulos deve considerar necessariamente seu modo de publicação.

A observação que Balzac faz a Latouche confirma que um escritor, mesmo que ainda seja um novato, como é o caso de Balzac em 1829 , escreve pensando em um destinatário cuja aparência ele conhece, o volume do gabinete de leitura ou então, sonho ainda inacessível, o in-8, o volume nobre por excelência. Agasalhar-se no couro fulvo de um belo in-8 a fim de ser visto por todos, esta era a ambição do futuro pai da Comédie Humaine antes que o romance-folhetim viesse a impor sua lei e conferir ao volume "Charpentier", o "Grande in-18 inglês chamado 'Jesus", a função doravante atribuída ao metro-padrão da glória literária. É exatamente o que afirma Théodore de Banville, quando escreve a Michel Lévy, em 1858, comunicando-lhe suas mais íntimas aspiraçóes: "Como o senhor sabe, meu sonho sempre foi o de publicar minha poesia em sua biblioteca de 1 franco, pois esta, para mim que sou o pássaro raro dos poetas, representa a Popularidade" ${ }^{12}$. Ainda que neste caso estejamos longe do capítulo de romance, uma vez que se trata de poesia, a súplica de Banville coincide com a secreta esperança de Balzac, mas desta vez o pequeno volume triunfou sobre seu rival, embora o in-18 das coleçóes vendidas por 1 franco apresentasse um "belo papel acetinado" de que não dispunha o antigo in-12, que não deixa de lhe ser comparável por seu tamanho muito parecido.

Tradução

Celina Maria Moreira de Mello Pedro Paulo Garcia Ferreira Catharina Universidade Federal de Rio de Janeiro

12 Théodore de Banville a Michel Lévy, citado em MOLLIER, 1984, p. 255. 


\section{Referências bibliográficas}

BALZAC, Honoré de. Correspondance. Paris: Classiques Garnier, 19601969, 5 vol.

BROOKS, Peter. L'imagination mélodramatique. Balzac, Henry James, le mélodrame et le mode de l'excès [1976]. Paris: Classiques Garnier, 2011 [trad. fr].

César Falempin ou les idoles d'argile par l'auteur de Jérôme Paturot. Paris: Michel Lévy frères, 1845, 2 vol.

COLIN, Claire; CONRAD, Thomas; LEBLOND, Aude (dir.). Pratiques et poétiques du chapitre; du XIXe au XXI siècle. Rennes: PUR, 2013.

DUMASY, Lise. Le roman-feuilleton français au XIXe siècle. Paris: PUF, 1989. (Que sais-je ?)

FEBVRE, Lucien. Le problème de l'incroyance au XVI siècle. La religion de Rabelais. Paris: Albin Michel, 1947.

GALVAN, Jean-Pierre. Les Mystères de Paris. Eugène Sue et ses lecteurs. Paris: L'Harmattan, 1998, 2 vol.

GLEIZE, Joëlle. Balzac et la totalisation des intelligences. L'Année balzacienne. Paris: PUF, n. 11, 2010/1: 97-109.

GUISE, René. Le roman-feuilleton (1830-1848). La naissance d'un genre. Nancy: Université de Nancy, 1975. (Thèse de doctorat ès-lettres).

HOGGART, Richard. The Uses of Literacy. Aspects of working-class life with special references to publications and entertainments. London: Chatto and Windus, 1957.

JENKINS, Henry. La culture de la convergence: des médias aux transmédia [2006]. Paris: Armand Colin, 2013 [trad. fr.].

KALIFA, Dominique. La culture de masse en France. T. 1. 1860-1930. Paris: La Découverte, 2001. (Repères)

. et al. (dir.). La civilisation du journal. Histoire culturelle et littéraire de la presse française au XIX ${ }^{e}$ siècle. Paris: Nouveau Monde, 2011.

LECLERC, Yvan. Crimes écrits. La littérature en procès au XIX siècle. Paris: Plon, 1991.

LYON-CAEN, Judith. La lecture et la vie. Les usages du roman au temps de Balzac. Paris: Tallandier, 2006.

MAUPASSANT, Guy de. Correspondance. Euvres complètes. Paris: Edito-service SA, 1973, t. III. 
McKENZIE, Donald F. La bibliographie et la sociologie des textes [1986]. Paris: Éditions du Cercle de la Librairie, 1991 [trad. fr.].

MIGOZZI, Jacques (dir.). De l'écrit à l'écran. Littératures populaires, mutations génériques, mutations médiatiques. Limoges: PULIM, 2000.

MIRECOURT, Eugène de. Fabrique de romans. Maison Alexandre Dumas et Compagnie. Paris: Chez tous les marchands de nouveautés/Imprimerie de Hauquelin et Bautruche, 1845.

MOLLIER, Jean-Yves. Une autre histoire de l'édition française. Paris: La fabrique éditeur, 2015.

. Le parfum de la Belle Époque. In: RIOUX, Jean-Pierre ; SIRINELLI, Jean-François (dir.). La culture de masse en France; de la Belle Époque à aujourd'hui. Paris: Fayard, 2002, pp. 72-115.

. L'édition en Europe avant 1850. Balzac et la propriété littéraire internationale. L'Année balzacienne, n. 13, 1992, pp. 157-173.

. Michel et Calmann Lévy ou la naissance de l'édition moderne 18361891. Paris: Calmann-Lévy, 1984.

MOLLIER, Jean-Yves ; SIRINELLI, Jean-François; VALLOTON, François (dir.). Culture de masse et culture médiatique en Europe et dans les Amériques. 1860-1940. Paris: PUF, 2006.

MORETTI, Franco. Atlas du roman européen. 1800-1900 [1997]. Paris: Seuil, 2000 [trad. fr].

PARENT-LARDEUR, Françoise. Lire à Paris au temps de Balzac. Les cabinets de lecture à Paris au temps de Balzac. 1815-1830. Paris: EHESS, 1981.

THÉRENTY, Marie-Ève. La littérature au quotidien. Poétiques journalistiques au XIX siècle. Paris: Seuil, 2007.

. Mosaïques. Etre écrivain, entre presse et roman (1829-1836). Paris: Honoré Champion, 2003.

THÉRENTY, Marie-Ève; VAILLANT, Alain. 1836. L'An I de l'ère médiatique. Analyse littéraire et historique de 'La Presse' de Girardin. Paris: Nouveau monde, 2001.

THIESSE, Anne-Marie. Le roman du quotidien. Lecteurs et lectures populaires à la Belle Époque. Paris: Imago, 1984.

VAREILLE, Jean-Claude. Le roman populaire français. 1789-1914. Limoges: PULIM, 1994. 
Jean-Yves Mollier é professor Emérito de História Contemporânea da Universidade de Versailles Saint-Quentin-en-Yvelines, França, onde dirigiu por muitos anos o Centre d'histoire culturelle des sociétés contemporaines. Tem dedicado sua obra ao estudo da história do livro e da edição, das práticas de leitura e da censura do século XVIII ao século XXI. Autor de Edição, Imprensa e Poder na França do Século XX (Edusp; Unifesp, 2015); Edição e revolução: leituras comunistas no Brasil e na França (com Marisa Midori Deaecto, Editora UFMG; Ateliê Editorial, 2013); O Dinheiro e as Letras: História do Capitalismo Editorial (Edusp, 2010); O Camelô: Figura emblemática da comunicação (Edusp, 2009) e muitos outros títulos de referência para os estudos sobre a história do livro e da edição. E-mail: jean-yves.mollier@uvsq.fr

Recebido em: 16/01/2018

Aceito em: 15/07/2018 